\title{
Chapter \\ Psychiatry and Mentally Disordered Offenders in England
}

\author{
John Gunn and Pamela Taylor
}

\section{Introduction}

In 1960, offenders with mental disorder were still sometimes treated by general psychiatrists but, more often, they were sent to prison, occasionally to special (high-security) hospitals where, in the 1960s, nursing staff dressed as prison officers. Consultant psychiatrists there were generally as isolated from mainstream psychiatry as their patients, neither specially trained nor recognised as trainers of future specialists. All that has changed.

In 1946, Aubrey Lewis became the first full-time professor of psychiatry at the Maudsley and took the Institute of Psychiatry into the University of London. He appointed first Norwood East, who gave lectures at the Maudsley before the war, and then Trevor Gibbens, returning from five years as a prisoner of war, as senior lecturers in 'forensic psychiatry'. Why 'forensic'? It is not what East wrote about - he was just treating criminals, ${ }^{1}$ but the term has stuck. The East and Hubert report had advocated the development of a specialist psychiatric prison in England (Grendon), ${ }^{2}$ although when it was finally opened in 1962 it did not, as he suggested, specialise in treating prisoners with psychosis but became a therapeutic community; ${ }^{3}$ but he had long recognised the need to treat 'non-sane, non-insane' prisoners. They abound in every prison system in the world.

In 1960, the Department of Health recognised only two consultants in Britain as forensic psychiatrists: Trevor Gibbens, who became the first UK professor of forensic psychiatry, and Peter Scott, who was allowed to 'borrow' two general psychiatry beds at the Maudsley Hospital before acquiring a joint appointment between the Maudsley and Brixton prison, but this gave little scope for effecting prisoner transfers to hospital. Their clinical work was the assessment of juveniles who were before the courts.

The abolition of the death penalty in Britain allowed the proper development of assessment and treatment of offenders. The last executions were in 1964 and the death penalty was abolished even for treason in 1998. Until abolition, it was hard for psychiatrists to remain completely objective in reports for the courts, feeling, almost inevitably, involved in the grisly process of trying to save the lives of condemned individuals. Professor Denis Hill, an expert on epilepsy, assessed Derek Bentley, a young man with epilepsy and intellectual disability, who was hanged in 1953; though involved with a homicide, he did not actually kill anyone. This experience left Professor Hill determined to improve society's understanding of relationships between mental disorder and crime and to develop forensic psychiatry when he succeeded Sir Aubrey Lewis at the Institute of Psychiatry. 


\section{Professional Developments}

In 1978, Trevor Gibbens's chair was established and, in 1988, an independent Department of Forensic Psychiatry was created at the Maudsley. Between 1990 and 2002, seven forensic psychiatry chairs were created around England, almost invariably funded by the NHS; but British universities were becoming business-oriented and their core funding was decreasingly available for developing academic subjects, like forensic psychiatry, which did not attract large grants. The Department of Health set up a Special Hospitals Research Unit in 1970, initially funding a special hospitals' case register but then, under the Special Hospitals Service Authority (SHSA), more wide-ranging projects and a new chair. As special hospital management was devolved, so the research monies passed into the National Programme on Forensic Mental Health. This both built knowledge and developed young academics across relevant disciplines, but success was rewarded with the removal of the protected streaming in 2007. ${ }^{4}$ Since then, British academic posts generally have come under increasing threat, ${ }^{5}$ thus hampering future research developments in psychiatry and, as a smaller specialty, forensic psychiatry is likely to suffer disproportionately.

The vision of specialist clinical development, however, began back in 1963, when the then two recognised forensic psychiatrists and thirteen others met, under the chairmanship of Dr Patrick McGrath, then medical superintendent of Broadmoor Hospital. They resolved to form a forensic subcommittee of the Royal Medico-Psychological Association. After the inauguration of the Royal College of Psychiatrists in 1971 this became a College section, holding its first two-day academic meeting in Birmingham, attended by tens of people. In 1997, it became a College faculty, now with an annual conference attendance of more than 400 people. Training continues, evolving alongside service development, with the three-year higher training curriculum under review at the time of writing.

\section{Liberalising Legal and Institutional Systems}

The Mental Health Act 1959, implemented in 1960, placed emphasis on voluntary psychiatric treatment. In 1961, the minister of health, Enoch Powell, launched the 'care in the community' policy - with one of his famous melodramatic speeches advocating the closure of hospitals and a drop in bed numbers of around 75,000 within 15 years. $^{6}$

The care in the community ideal was that most psychiatric work would be done in the outpatient clinic or at home by visiting nurses, with rare need for short-term admissions to small general hospital units. This is probably the best approach if well-resourced and stable families can work with highly skilled staff, quickly available at any moment of crisis. It was hardly a novel idea. Towards the end of the eighteenth century, this is precisely how Mary Lamb was managed after killing her mother while psychotic. ${ }^{7}$ Few families of people with severe mental disorders, however, have the emotional or social resources to do this and good community clinical care is expensive. Governments have never provided adequate resources nor apparently have understood the extent, complexity and durability of need. Worse, as care gaps opened in England, the then three special hospitals - Broadmoor, Rampton and Moss Side - were increasingly asked to take more patients, ironically because of the liberalising effect of the Mental Health Act 1959. ${ }^{8}$ By the early 1970s, these hospitals were grossly overcrowded - with patients sleeping in corridors. A fourth was built - Park Lane (later combined with Moss Side, becoming Ashworth).

To some extent, such problems had been foreseen. In the same year as Enoch Powell's speech, the Emery Report recommended that regional hospital boards should include secure 
units in the range of local hospital provision - nothing happened. ${ }^{9}$ In 1974, the Glancy Report recommended the building of a secure hospital unit in each NHS region of England and Wales, with approximately 20 secure beds per million population (about 1,000) - not implemented. ${ }^{10}$

Matters came to a head when Graham Young, admitted to Broadmoor hospital at the age of fourteen after poisoning several family members and perhaps suffering from autism, was released after nine years there. ${ }^{11}$ His intense preoccupation with heavy-metal poisons continued, he found employment in a photographic works, with access to thallium, and he poisoned several colleagues. At his second trial, he was found fully responsible for his actions and imprisoned. The home secretary, Reginald Maudling, established two inquiries on the same day - an inquiry into discharge arrangements from special hospitals, to be chaired by Sir Carl Aarvold, ${ }^{12}$ and a more wide-ranging inquiry into service provision, to be chaired by Lord Butler, a previous home secretary.

\section{The Growth of Mental Health Services for Offenders}

The Butler Report included recommendations for caring for and treating offenders with mental disorder. ${ }^{13}$ The committee, which included Denis Hill, from the Institute of Psychiatry, other psychiatrists, a lawyer and a criminologist, found the overcrowding in the high-secure hospitals so serious that they issued an interim report in 1974, recommending a medium-security hospital unit for every health region, just as Emery and Glancy had done, but with twice the Glancy number of beds. Unlike its predecessors, the Butler Report was not ignored. The secretary of state for health and social services, Barbara Castle, accepted the urgent need and allocated funds for 1,000 medium-security beds. By 1978, some interim units had opened and, by the early 1980s, there was steady growth, although some regions resisted on the advice of their general psychiatrists, even diverting the money to general medical and surgical services. One real problem was training clinicians of all disciplines, especially psychiatrists, quickly enough to staff the units. By 1990, almost all regions had provided purpose-designed units.

The Butler Report is perhaps principally remembered for launching these developments, but it ranged much more widely. Around thirty years before Corston and Bradley, ${ }^{14}$ it was advocating diversion from the criminal justice system for appropriate cases and calling for explicit care and treatment pathways. Frameworks for coercion and treatment contracts in the community were considered in depth; they expressed the need for research into the effectiveness of 'psychiatric probation orders', which applies also to their current counterparts - community sentences with treatment requirements. Indeed, Butler emphasised 'the need to plan evaluative studies as soon as any new regime or form of treatment has been decided on'. The report also said that 'the terms "psychopath" and "psychopathic disorder" are unsatisfactory'. These have been removed from disorder classification systems and UK legislation, but they are still used casually and pejoratively. One recommendation belatedly taken up in the Criminal Justice Act 2003 was an indeterminate sentence for public protection (IPP). This proved to be a serious mistake and was repealed in 2012. A Channel 4 documentary, Crime and Punishment, captures the awful legacy of this experiment. ${ }^{15}$

A key recommendation that has borne fruit was on co-operation between professions. Forensic psychiatry embraced that most systematically under the Multi-Agency Public Protection Arrangements (MAPPA), introduced in the Criminal Justice and Court Services Act 2000 and strengthened under the Criminal Justice Act 2003. The Forensic Psychiatry Faculty of the Royal College provided guidance for clinicians. ${ }^{16}$ 
A further wide-ranging review, ${ }^{17}$ chaired by Dr John Reed, included separate, supplementary reports on academic development, community treatment, finance, hospital provision, learning disability and autism, special service groups (e.g. women, under-eighteenyear-olds), prisons, research, people with special needs, staffing and training and services for people from black and ethnic minority groups. The enunciated principles still hold good:

patients should be cared for [according] to the needs of individuals, as far as possible in the community, rather than institutional settings, under ... no greater security than is justified by the degree of danger they present to themselves or others, in such a way as to maximise ... chances of ... an independent life, as near as possible to their own homes or families if they have them.

Also:

there should be strong proactive equal opportunity policies relating to race and culture in all agencies involved. ... ethnic minority communities should be involved in the planning, development and monitoring of services for mentally disordered offenders.

Elements of the review relating to people with mental illness and inpatient provision were generally followed through well. The Special Hospitals Service Authority assumed management of the high-security hospitals from direct Department of Health control between 1989 and 1996, before handover to local Health Trusts; the special hospital population was substantially reduced. The vision of better treatment of offenders with personality disorder was deferred to a new working group but that of reducing numbers of people with mental disorder in prison was not achieved. One recommendation has resonated forward:

services dealing with mentally disordered offenders [should] take account of the needs of victims.

Perhaps inevitably, funding for the development of the new services created resentment among some other psychiatrists. Perhaps uniquely in the history of medicine, one pair called for forensic psychiatry to be abolished:

forensic services, as they currently stand, primarily exist to fulfil political demands for a visible and coercive response to risk. ... Meanwhile the poorly adherent, treatment resistant patients ... come in and out of general acute wards, frequently abusing and hitting staff on their way ... The reluctance of adult general psychiatry to accept low secure cases into this environment is often perceived as obstructive by forensic specialists. ... General psychiatrists, in return, see forensic units as awash with resources and spoilt by the luxury of selectivity based on the specious definition of caseness. ${ }^{18}$

In fact, this outburst reflected old-fashioned attitudes towards mentally disordered offenders, implying that they should be treated in prisons, ${ }^{19}$ and the problem that general psychiatry is under-resourced.

\section{Prisons}

While truly innovative work has occurred in prisons since 1960, the situation for the average prisoner has worsened. Grendon prison was opened as a therapeutic community in 1962, its first governor a senior prison doctor - William Gray. Essential criteria were that men had to volunteer and be violence-free or leave. Grendon was evaluated by the Institute of 
Psychiatry; ${ }^{20}$ prisoners were assessed before, during and after treatment. On all the main measures - psychiatric state, symptoms, personality and attitudes to authority figures and to self - large changes were found between the first and final assessments. At baseline, twothirds of the men had clinically significant psychiatric disorder but just one-third at final assessment; cases of moderate/marked severity dropped from 37 per cent of the total to 18 per cent. Although criminal attitudes also changed substantially, a ten-year follow-up of reoffending was equivocal, but, of course, relevant continuation work had rarely been available to the men. ${ }^{21}$ Subsequent studies confirmed positive effects. ${ }^{22}$ That Grendon continues and a second therapeutic community was opened at Dovegate prison in 2001 also indicate success.

Other prison developments were less positive. In 1960, 25,000 people were in UK prisons. By 1972, there were 40,000 in England and Wales, when an Institute of Psychiatry study of their mental health needs found that about one-third were 'psychiatric cases' ${ }^{23}$ A second epidemiological study in 1990 suggested that about 45 per cent of the prison population needed psychiatric treatment, about 1,000 of them as hospital inpatients. ${ }^{24}$ Later, an Office for National Statistics survey suggested that these figures were underestimates, reporting 7 per cent with psychosis, more than 60 per cent with 'personality disorder', 63 per cent with alcohol use problems and 66 per cent with other drug problems. ${ }^{25}$

By 2020, the prison population in England and Wales was about 83,000 but 40 per cent cuts to prison staff in 2013 in publicly run prisons in England and Wales undid some undoubted previous service improvements. ${ }^{26}$ Following these cuts, prisoner suicide, selfharm and violence rates rose to the highest levels since recording began in 1978, with 57,968 incidents of self-harm in 2018/19 alone. $^{27}$ Her Majesty's Chief Inspector of Prisons (HMCIP), in his annual report of 2016-17, observed:

By February this year we had reached the conclusion that there was not a single establishment that we inspected in England and Wales in which it was safe to hold children and young people. ${ }^{28}$

Qualitative evaluation of adult prisoner experience suggests that it is similar to the 'institutionalism' of the dying asylums. ${ }^{29}$

What was going well before this false cost-saving exercise? Prison officers had generally moved towards more truly safeguarding and respectful practices, perhaps a halo effect from the Grendon initiative. Indeed, HMCIP found this still true even when the environment was otherwise failing, citing 74 per cent of prisoners asserting they were being treated respectfully. ${ }^{30}$ Medical services in prisons had changed radically. When the NHS was established in 1948, the prison medical service had remained separate and answerable to the Home Office. Standards of care were poor, ${ }^{31}$ probably due to its isolation from the mainstream NHS. ${ }^{32}$ In 2002, it was announced that budgets for health care in public sector prisons would be transferred to the Department of Health, with full commissioning responsibility to be devolved to primary care trusts in stages; this process was completed in 2006. In 2007, HMCIP concerns had shifted:

When mental health in-reach teams rode to the rescue of embattled prison staff they found a scale of need which they had neither foreseen nor planned for.

Four out of five mental health in-reach teams felt that they were unable to respond adequately to the range of need. 
... [in prison] need will always remain greater than the capacity, unless mental health and community services outside prison are improved and people appropriately directed to them: before, instead of and after custody. ${ }^{33}$

The importance of a long-term, comprehensive approach was underscored in guidance published as the Offender Mental Health Care Pathway. ${ }^{34}$ The Royal College of Psychiatrists set up a Quality Network for Prison Mental Health Services in $2015,{ }^{35}$ which many prisons have joined, and set up an 'enabling environments' award.

\section{From 'Dangerousness' to 'Risk'}

Until 1960, dangerousness was a popular concept in psychiatry. It was the preferred term for the Butler Committee in 1975, and the British Journal of Psychiatry carried Peter Scott's guidance for psychiatrists on 'assessing dangerousness in criminals' ${ }^{36}$ In the 1970 s, criminologists were very interested in dangerousness, and the Howard League sponsored a report on it, ${ }^{37}$ exposing flaws in attempts until then to measure dangerousness as an individual characteristic. The concept of 'risk' became more popular. Psychologists laboured to provide tools to help clinicians, but systematic reviews have pooled data to find their predictive value limited, ${ }^{38}$ the popular psychopathy checklist (PCL-R) producing the lowest of all as a geographer, ${ }^{39}$ working on the prevention of road accidents, observed:

Human behaviour will always be unpredictable; it will always be responsive to other human behaviour, including yours. ${ }^{40}$

Nevertheless, the psychologists' tools do give prompts, structure and transparency in coming to decisions. Providing that a risk assessment is used 'as an aid to clinical decision making and not a substitute for it', ${ }^{41}$ in conjunction with appropriate risk management and regular re-evaluation, these tools are helpful, although we must remain mindful of advice from a US forensic psychiatrist:

A society sincerely concerned about reducing violence will seek broad measures that address both known risks for violence among persons both with and without mental health problems. $^{42}$

\section{Miscarriages of Justice}

Forensic psychiatry and psychology in England became particularly concerned with false confessions after a 1972 incident in England when an eighteen-year-old with intellectual disability and two young teenagers were wrongly convicted of homicide or arson, largely on confession evidence. ${ }^{43}$ A subsequent case series of sixty estimated that less than half of suspects have a normal mental state at the time of police interview. ${ }^{44}$ A Royal Commission on Criminal Procedure followed, leading to the Police and Criminal Evidence Act 1984 (PACE) ${ }^{45}$ This provided rules for police interviews, with a requirement for the presence of a 'responsible adult' in the event of mental illness or disability. Further serious miscarriages of justice followed, however, with a common thread of police under pressure to solve a notorious crime providing flawed evidence. The release of six men wrongly convicted of the Birmingham IRA pub bombings led to the 1993 Royal Commission on Criminal Justice. ${ }^{46}$ James MacKeith and Gisli Gudjonsson provided clinical and research evidence for added safeguards. ${ }^{47}$ A new Criminal Cases Review Commission was established. ${ }^{48}$ 
Psychological damage to victims of miscarriage of justice adds to the social turmoil and is particularly difficult to treat in the face of constant re-traumatisation as inquiries follow. ${ }^{49}$ In personal experience of one case alone (PJT), hearings on compensation, inquiries into the miscarriage, criminal cases against lay witnesses and police and further inquiry into why the latter failed lasted nearly thirty years.

\section{Victim-Centred Work}

Recognition of the importance of work with victims of harmful behaviours has grown in terms of respect for their wishes and needs and also from the perspective of preventing further harms.

Countless studies have now linked adverse childhood experiences (ACEs) with later violence and/or mental disorder, but Cathy Spatz Widom pioneered prospective study relating to verified abuse. ${ }^{50}$ The mystery is that about half of such children do not become violent - why? Caspi and Moffitt identified a moderating effect of MAOA-LPR polymorphism; ${ }^{51}$ in the prospective Dunedin birth cohort study, 85 per cent of boys with a genotype conferring low MAOA levels who had suffered severe maltreatment became antisocial. In England, Walsh and colleagues showed the perhaps comparable vulnerability of people with severe mental illness to being violently attacked, ${ }^{52}$ not unique to the UK. ${ }^{53}$

In 1985 Shapland and colleagues highlighted the travesty of treating victims of crime merely as witnesses. ${ }^{54}$ Victim support services had been set up in the UK, probably the first in Bristol in 1971, but only tiny numbers of victims benefited. ${ }^{55}$ The Home Office published a Victim's Charter in 1990, which established the centrality of victims' rights, and probation services developed expertise in victim support. ${ }^{56}$ Eventually, the Domestic Violence, Crime and Victims Act 2004 put those rights into law and extended them to victims of offenders with mental disorder. Such victims have the right to know about tribunal hearing dates and to submit written or in-person evidence. For victims of offender-patients on Mental Health Act restriction orders, the system is adequate; but independent victim support is not guaranteed for unrestricted cases.

Over and above a duty of care to victims, we must learn from their experiences. The Crime Survey for England and Wales (formerly the British Crime Survey, now devolved) is a household survey giving a more accurate picture of criminal activity than criminal conviction statistics. ${ }^{57}$ In psychiatry, we have learned from individual inquiries after homicide. These followed Jayne Zito's drive to have something of value emerge from her husband's killing in 1992 by a man with inadequately treated schizophrenia(see also Chapters 23 and 27). ${ }^{58}$ The Zito Trust closed in 2009, considering its specific goals met; Hundred Families has taken up some of its roles, ${ }^{59}$ including being a repository for individual inquiries after homicide. Early collective evidence from these confirmed that, even with hindsight advantage, perhaps only 25 per cent of the homicides could have been predicted, but two-thirds might have been prevented with adequate treatment. ${ }^{60}$ This fits with a growing understanding that when psychosis confers added risk of violence it is when it is untreated. ${ }^{61}$ Adequate, timely treatment is evidenced on economic grounds too. ${ }^{62}$

\section{International Exchange}

Services for mentally disordered offenders are, in some respects, more culture- and countrybound than other medical specialties. Law and practice and court structures differ even between constituent UK countries. A powerful instrument supporting positive change in 
the UK, however, has been the European Convention on Human Rights. ${ }^{63}$ This has underpinned many legislative changes since 1970, including the right in mental health law to appeal against detention even after restrictions on discharge have been imposed by a criminal court.

Many countries have had to reappraise after some service lapses. In England, this has related mainly to high-security hospitals - Rampton and Ashworth both had inquiries after allegations of cruelty to patients and Ashworth again after finding children visiting a personality disorder unit. ${ }^{64}$ The latter simply excoriated anyone even marginally involved, from the secretary of state on down. Another report on security at all three English hospitals, led by a former director of the prison service, resulted in controversial and high expenditure on extra walls or fences at two of the hospitals. ${ }^{65}$

As other countries faced problems, British experience was occasionally called in, for example when New Zealand had to respond to over-restrictive and impoverished practices in its then high-security hospital. ${ }^{66}$ Service development followed on the Butler mediumsecurity model - with relevant cultural modifications, from which we, in turn, now learn. In other areas, forensic psychiatrists themselves have identified service gaps and innovated. Paul Mullen left the UK for Australasia where, in addition to secure inpatient services, he set up specific problem-behaviour clinics for people who provoke avoidance behaviours in many clinicians - including vexatious litigants, the fixated, the morbidly jealous and stalkers. ${ }^{67}$ This model has recently been brought back to the UK and developed further, for example in a National Stalking Clinic and new gaps met as required and spread further internationally. ${ }^{6}$

International academic collaborations have been fostered through the International Association of Forensic Mental Health Services from 2000, ${ }^{69}$ showcasing interdisciplinary research worldwide, while in Europe the Ghent Group, established in 2004, provides support to psychiatrists assessing and treating mentally disordered offenders through an annual meeting discussing services, educational visits and a training programme. ${ }^{70}$

\section{Conclusion}

The period 1960-2010 has generally been one of growth for services for offenders with mental disorder. There have been errors and we are sensitive to ever present risks from both external threats and internal failings that could damage safety, trust and progress.

We have established the first charity dedicated to research in the field - Crime in Mind.$-^{71}$ The charity finds it difficult to attract funding for the same reasons that forensic psychiatry does not attract funding in universities but it has managed to start a small programme of seminars relating to research issues and even to develop small-scale research projects.

\section{Key Summary Points}

- By the 1960s, some psychiatrists had begun to specialise in work with mentally disordered offenders but the term 'forensic psychiatry' was not used anywhere except at the Maudsley Hospital. In the UK, such work has demonstrated a highly developed capacity for inter-agency working.

- In 1978, the first UK professorial chair was established and in 1988 an independent Department of Forensic Psychiatry was created at the Maudsley Hospital. Between 1990 and 2002, seven forensic psychiatry chairs were created around England, almost 
invariably funded by the NHS; but British universities were becoming business-oriented and their core funding was decreasingly available for developing academic subjects, like forensic psychiatry, which did not attract large grants.

- The Butler Report, in 1975, ${ }^{72}$ included recommendations for caring for and treating offenders with mental disorder. A further wide-ranging review, chaired by Dr John Reed in $1992,{ }^{73}$ included separate, supplementary reports on academic development, community treatment, finance, hospital provision, learning disability and autism, special service groups (e.g. women, under-eighteen-year-olds), prisons, research, people with special needs, staffing and training and services for people from black and ethnic minority groups. One problem was training clinicians of all disciplines, especially psychiatrists, quickly enough to staff the units.

- In 1960, 25,000 people were in UK prisons. By 1972, there were 40,000 in England and Wales, when a study found that about one-third were 'psychiatric cases'. By 2020, the prison population in England and Wales was about 83,000 but 40 per cent cuts to prison staff in 2013 undid some undoubted service improvements. Following these cuts, prisoner suicide, self-harm and violence rates rose to the highest levels since recording began in 1978. Qualitative evaluation of adult prisoner experience in 2020 suggests that it is similar to the 'institutionalism' of the dying asylums.

- Psychological damage to victims of miscarriage of justice adds to the social turmoil and is particularly difficult to treat in the face of constant re-traumatisation as inquiries follow. Forensic psychiatry and psychology in England became concerned with false confessions. In general, recognition of the importance of work with victims of harmful behaviours has grown in terms of respect for their wishes and needs and also from the perspective of preventing further harms.

\section{Notes}

1. W. N. East, Society and the Criminal. London: HMSO, 1949.

2. W. N. East and W. H. Hubert, Report on the Psychological Treatment of Crime. London: HMSO, 1939.

3. J. Gunn, G. Robertson, S. Dell and C. Way, Psychiatric Aspects of Imprisonment. London: Academic Press, 1978.

4. K. Soothill, K. Harney, A. Maggs and C. Chilvers, The NHS forensic mental health R\&D programme: Developing new talent or maintaining a stage army? Personality and Mental Health (2008) 2: 183-91, https:// doi.org/10.1002/pmh.44.

5. Medical Schools Council, Survey of Medical Clinical Academic Staffing Levels, 2018, www.medschools.ac.uk /our-work/publications?Category=2265\&page $=1$.

6. J. E. Powell, Enoch Powell's Water Tower Speech, 1961, www.studymore.org.uk.

7. K. Watson, The Devil Kissed Her: The Story of Mary Lamb. London: Bloomsbury, 2004.

8. P. Bowden, Review of Report on the work of the Prison Department, Home Office 1976 and Statistical Tables Cmnd. \& Cmnd 6884, HMSO. Bulletin of the Royal College of Psychiatrists, 13-15 November 1977; T. Black, Broadmoor Hospital: A unique facility. The Psychologist (2013) 26: 908-10.

9. Ministry of Health, Special Hospitals: Report of a Working Party [Emery Report]. London: HMSO, 1961.

10. Department of Health and Social Security (DHSS), Revised Report of the Working Party on Security in NHS psychiatric hospitals [Glancy Report]. London: HMSO: 1974.

11. P. Bowden, Graham Young (1947-90); the St. Albans poisoner: His life and times. Criminal Behaviour and Mental Health (1996) Supplement: 17-24 
12. C. Aarvold, D. Hill and G. Newton, Report on the Review of Procedures for the Discharge and Supervision of Psychiatric Patients Subject to Special Restrictions, Cmnd 5191. London: HMSO, 1973.

13. Home Office and DHSS, Report of the Committee on Mentally Abnormal Offenders [Butler Report], Cmnd. 6244. Final report. London: HMSO, 1975.

14. J. Corston, A Report by Baroness Jean Corston of a Review of Women with Particular Vulnerabilities in the Criminal Justice System. London: Home Office, 2007, www.newsocialartschool.org/pdf/Corston-pt-1.pdf; K. Bradley, The Bradley Report: Lord Bradley's Review of People with Mental Health Problems or Learning Disabilities in the Criminal Justice System. London: Department of Health, 2009, https://webarchive .nationalarchives.gov.uk/20130105193845/www.dh.gov.uk/prod_consum_dh/groups/dh_digitalassets/docu ments/digitalasset/dh_098698.pdf.

15. L. Martin, Crime and Punishment: What time it's on Channel 4 tonight and what to expect from the documentary series. iNews, 23 September 2019, https://inews.co.uk/culture/television/crime-andpunishment-when-its-on-c4-tonight-what-to-expect-from-the-doc-series-339167.

16. R. Taylor and J. Yakeley, Working with MAPPA: Guidance for Psychiatrists in England and Wales. Faculty Report No. FR/FP/01 2013, www.rcpsych.ac.uk/docs/default-source/members/faculties/forensic-psychiatry /forensic-fp-01-final2013.pdf?sfvrsn=a3c2ba8b_2.

17. Department of Health and Home Office, Review of Health and Social Services for Mentally Disorder Offenders and Others Requiring Similar Services [Reed Report], Cm2008. . London: HMSO, 1992.

18. T. Turner and M. Salter, Forensic psychiatry and general psychiatry: Re-examining the relationship. Psychiatric Bulletin (2008) 32: 2-6, https://doi.org/10.1192/pb.bp.106.009332.

19. Bowden, Review of Report on the work of the Prison Department; R. K. W. Reeves, Regional medium security units: Solution or disaster? Bulletin of the Royal College of Psychiatrists, Feb, 33-35, 1978.

20. Gunn, Robertson, Dell and Way, Psychiatric Aspects of Imprisonment.

21. G. Robertson and J. Gunn, A ten year follow-up of men discharged from Grendon prison. British Journal of Psychiatry (1987) 151: 63-38. https://doi.org/10.1192/bjp.151.5.674.

22. E. Genders and E. Player, Grendon: A Study of a Therapeutic Prison. Oxford: Oxford University Press, 1995.

23. Gunn, Robertson, Dell and Way, Psychiatric Aspects of Imprisonment.

24. J. Gunn, A. Maden and M. Swinton, Mentally Disordered Prisoners. London: Home Office, 1991.

25. N. Singleton, H. Meltzer, R. Gatward, J. Coid and D. Deassy, Psychiatric Morbidity among Prisoners in England and Wales. London: HMSO, 1998.

26. Ministry of Justice, National Offender Management Service Workforce Statistics, 2017, www.gov.uk/govern ment/collections/national-offender-management-service-workforce-statistics.

27. S. McAllister, Prisons and Probation Ombudsman Annual Report 2018-19. Open Government Licence CP175. 2019 https://s3-eu-west-2.amazonaws.com/ppo-prod-storage-1g9rkhjhkjmgw/uploads/2019/10/PP O_Annual-Report-2018-19_WEB-final-1.pdf.

28. HM Chief Inspector of Prisons, Annual Report: 2016-17. London: HM Inspectorate of Prisons, 2017. https:// assets.publishing.service.gov.uk/government/uploads/system/uploads/attachment_data/file/629719/hmipannual-report-2016-17.pdf.

29. S. O’Connor, Z. Bezeczky, Y. Moriarty, N. Kalebic and P. J. Taylor, Adjustment to short-term imprisonment under low prison staffing. BJPsych Bulletin (2020) 44: 139-44, https://doi.org/10.1192/bjb.2020.2.

30. HM Chief Inspector of Prisons, Annual Report: 2016-17.

31. P. Scraton and P. Gordon, Causes for Concern: British Criminal Justice on Trial. Harmondsworth: Penguin, 1984; R. Ralli, Health care in prisons. In E. Player and M. Jenkins, eds, Prisons after Woolf: Reform through Riot. London: Routledge, 1994; HM Chief Inspector of Prisons, Patient or Prisoner? A New Strategy for Health Care in Prisons. London: Home Office, 1996. www.justiceinspectorates.gov.uk/hmiprisons/wp-content/upl oads/sites/4/2014/08/patient_or_prisoner_rps.pdf; J. Reed and M. Lyne, Inpatient care of mentally ill people 
in prison: Results of a year's programme of semi structured inspections. British Medical Journal (2000) 320: 1031-4, https://doi.org/10.1136/bmj.320.7241.1031.

32. R. Smith, Prisoners: An end to second class health care? Eventually the NHS must take over. British Medical Journal (1999) 318: 954, https://doi.org/10.1136/bmj.318.7189.954.

33. HM Chief Inspector of Prisons, The Mental Health of Prisoners: A Thematic Review of the Care and Support of Prisoners with Mental Health Needs, 2007. www.justiceinspectorates.gov.uk/hmiprisons/wp-content/uploa ds/sites/4/2014/07/Mental-Health.pdf.

34. Department of Health and National Institute for Mental Health in England. Offender Mental Health Care Pathway. London: Department of Health, 2005, https://bulger.co.uk/prison/mentalhealthpath.pdf.

35. National Offender Management Service \& NHS England, The Offender Personality Disorder Pathway Strategy, 2015, www.england.nhs.uk/commissioning/wp-content/uploads/sites/12/2016/02/opd-strategy-nov-15.pdf.

36. P. D. Scott, Assessing dangerousness in criminals. British Journal of Psychiatry (1977) 131: 127-42, https://doi .org/10.1192/bjp.131.2.127.

37. J. E. Floud and W. Young, Dangerousness and Criminal Justice. Cambridge: Cambridge University Press, 1981.

38. A. Buchanan and M. Leese, Detention of people with dangerous severe personality disorders: A systematic review. Lancet (2001) 358: 1955-9, https://doi.org/10.1016/S0140-6736(01)06962-8; J. P. Singh, S. Fazel, R. Gueorguieva and A. Buchanan, Rates of violence in patients classified as high risk by structured risk assessment instruments. British Journal of Psychiatry (2014) 104: 180-7, https://doi.org/10.1192/bjp.bp.113.131938.

39. J. P. Singh, M. Grann and S. Fazel, A comparative study of violence risk assessment tools: A systematic review and metaregression analysis of 68 studies involving 25,980 participants. Clinical Psychology Review (2011) 31: 499-513, https://doi.org/10.1016/j.cpr.2010.11.009.

40. J. Adams, Risk. London: University College London, 1995.

41. Department of Health, Best Practice in Managing Risk. Principles and Evidence for Best Practice in the Assessment and Management of Risk to Self and Others in Mental Health Services. London: Department of Health, 2007, http://webarchive.nationalarchives.gov.uk/+/www.dh.gov.uk/prod_consum_dh/groups/dh_d igitalassets/@dh/@en/documents/digitalasset/dh_076512.pdf.

42. D. Mossman, The imperfection of protection through detection and intervention: Lessons from three decades of research on the psychiatric assessment of violence risk. Journal of Legal Medicine (2009) 30: 109-40, https://doi.org/10.1080/01947640802694635.

43. H. A. P. Fisher, Report of an Inquiry by the Hon. Sir Henry Fisher into the Circumstances Leading to the Trial of Three Persons on Charges Arising out of the Death of Maxwell Confait and the Dire at 27 Doggett Road, London SE5. London: HMSO, 1977.

44. B. Irving and L. Hilgendorf, Police Interrogation Research Study No 1. The Psychological Approach. Royal Commission on Criminal Procedure. London: HMSO, 1980.

45. Royal Commission on Criminal Procedure, Report, Cmnd 8092. London: HMSO, 1991.

46. Royal Commission on Criminal Justice, [Runciman Report], Cm2263. London: HMSO, 1993, https://assets .publishing.service.gov.uk/government/uploads/system/uploads/attachment_data/file/271971/2263.pdf.

47. G. H. Gudjonsson and J. MacKeith, Retracted confessions: Legal, psychological and psychiatric aspects. Medicine Science and the Law (1988) 28: 187-94, https://doi.org/10.1177/002580248802800302;

G. H. Gudjonsson, Suggestibility Scales. London: Psychology Press, 2007.

48. Wikipedia, Criminal Cases Review Commission.

49. A. Grounds, Psychological consequences of wrongful conviction and imprisonment. Canadian Journal of Criminology and Criminal Justice (2004) 46: 165-82, https://doi.org/10.3138/cjccj.46.2.165.

50. C. S. Widom, The cycle of violence. Science (1989) 244: 160-6, https://doi.org/10.1126/science.2704995; C. S. Widom and M. G. Maxwell, An update on the 'Cycle of Violence'. National Institute of Justice Research in Brief, February 2001: 1-8, www.ncjrs.gov/pdffiles1/nij/184894.pdf. 
51. A. Caspi, J. McClay, T. E. Moffitt et al., Role of genotype in the cycle of violence in maltreated children. Science (2002) 297: 851-4, https://doi.org/10.1126/science.1072290.

52. E. Walsh, P. Moran, C. Scott et al., Prevalence of violent victimization in severe mental illness. British Journal of Psychiatry (2003) 183: 233-8, https://doi.org/10.1192/bjp.183.3.233.

53. L. A. Teplin, G. M. McClelland, K. M. Abram and D. A. Weiner, Crime victimization in adults with severe mental illness: Comparison with the National Crime Victimization Survey. Archives of General Psychiatry, (2005) 62: 911-21, https://doi.org/10.1001/archpsyc.62.8.911.

54. J. Shapland, J. Willmore and P. Duff, Victims in the Criminal Justice System. Aldershot: Gower, 1985.

55. R. I. Mawby and M. L. Gill, Crime Victims: Needs, Services and the Voluntary Sector. London: Tavistock, 1987; M. Hough and P. Mayhew, Taking Account of Crime: Key Findings from the Second British Crime Survey. Home Office Research Study No. 85. London: HMSO, 1985.

56. M. O. Rawsthorne, The probation service and victims of crime. Criminal Behaviour and Mental Health (1998) 8: 178-83, https://doi.org/10.1002/cbm.244.

57. C. Mirrlees-Black, Confidence in the Criminal Justice System: Findings from the 2000 British Crime Survey. Home Office Research Findings No. 137. London: Home Office, 2001.

58. J. Ritchie, D. Dick and R. Lingham, The Report of the Inquiry into the Care and Treatment of Christopher Clunis. London: TSO, 1994.

59. See Hundred Families website: www.hundredfamilies.org.

60. E. Munro and J. Rumgay, Role of risk assessment in reducing homicides by people with mental illness. British Journal of Psychiatry (2000) 176: 116-20, https://doi.org/10.1192/bjp.176.2.116.

61. R. Keers, S. Ullrich, B. DeStavola and J. W. Coid, Association of violence with emergence of persecutory delusions in untreated schizophrenia. American Journal of Psychiatry (2014) 171: 332-9, https://doi.org/10 .1176/appi.ajp.2013.13010134.

62. M. Senior, S. Fazel and A. Tsiachristas, The economic impact of violence perpetration in severe mental illness: A retrospective, prevalence-based analysis in England and Wales. The Lancet Public Health (2020) 5: e99e106, https://doi.org/10.1016/S2468-2667(19)30245-2.

63. European Court of Human Rights, European Convention on Human Rights, Strasbourg: Council of Europe, 2013, www.echr.coe.int/Documents/Convention_ENG.pdf.

64. Department of Health and Social Security, Report of the Review of Rampton Hospital, Cmnd. 8073. 11. London: HMSO, 1980; L. Blom-Cooper, M. Brown, R. Dolan, E. Murphy and Department of Health, Report of the Committee of Inquiry into Complaints about Ashworth Hospital, Cm.2028-1. London: HMSO, 1992; P. Fallon, R. Bluglass, B. Edwards, G. Daniels and Department of Health, Report of the Committee of Inquiry into the Personality Disorder Unit, Ashworth Special Hospital, Cm.4194-ii. London: TSO, 1999.

65. T. Exworthy and J. Gunn, Taking another tilt at high secure hospitals: The Tilt Report and its consequences for secure psychiatric services. British Journal of Psychiatry (2003) 182: 469, https://doi.org/10.1192/bjp .182.6.469.

66. K. H. Mason, H. Bennett and E. Ryan, Report of the Committee of Inquiry into Procedures Used in Certain Psychiatric Hospitals in Relation to Admission Discharge or Release on Leave of Certain Classes of Patients [Mason Report]. Wellington: Department of Health, 1988.

67. L. J. Warren, R. MacKenzie, P. E. Mullen and J. R. P. Ogloff, The problem behavior model: The development of a stalkers' clinic and a threateners' clinic. Behavioral Sciences and the Law (2005) 23: 387-97, https://doi .org/10.1002/bsl.593.

68. D. V. James, T. Kerrigan, R. Forfar, F. Farnham and L. Preston, The Fixated Threat Assessment Centre: Preventing harm and facilitating care. Journal of Forensic Psychiatry and Psychology (2010) 21, 521-36, htt ps://doi.org/10.1080/14789941003596981; D. V. James, F. R. Farnham and S. P. Wilson, The Fixated Threat Assessment Centre: Implementing a joint policing and psychiatric approach to risk assessment and management in public figure threat cases. In J. Reid Meloy and J. Hoffman, eds, International Handbook of Threat Assessment. New York: Oxford University Press, 2014; A. Underwood, R. Key, F. Farnham et al., Managing 
Perpetrators of Child Sexual Exploitation and Indecent Images of Children (IIOC): Understanding Risk of Suicide. London: Barnet, Enfield and Haringey NHS Mental Health Trust and NHS England, 2017, https://doi .org/10.13140/RG.2.2.35312.51204; F. R. Farnham and K. G. Busch, Introduction to international perspectives on the protection of public officials. Behavioral Sciences and the Law (2016) 34: 597-601, https://doi.org /10.1002/bsl.2266.

69. See the International Association of Forensic Mental Health Services (IAFMHS) website: www.iafmhs.org.

70. See the Ghent Group wesbite: www.ghentgroup.eu; J. Gunn and N. Nedopil, European training in forensic psychiatry. Criminal Behaviour and Mental Health (2005) 15: 207-13; P. J. Taylor, N. Wolfenden and N. Nedopil, Forensic psychiatry training in Europe. Die Psychiatrie (2013) 10: 181-7.

71. See the Crime in Mind website: www.crimeinmind.org; P. J. Taylor, C. Chilvers, M. Doyle, C. Gumpert, K. Harney and N. Nedopil, Meeting the challenge of research while treating mentally disordered offenders: The future of the clinical researcher. International Journal of Forensic Mental Health (2009) 8: 2-8, https://doi .org/10.1080/14999010903014564; C. Duggan, Looking from the outside: No substitute for rigorous evaluation. Criminal Behaviour and Mental Health (2019) 29: 189-95, https://doi.org/10.1002/cbm.2129.

72. Home Office and DHSS, Report of the Committee on Mentally Abnormal Offenders [Butler Report].

73. Department of Health and Home Office, Review of Health and Social Services for Mentally Disorder Offenders and Others Requiring Similar Services [Reed Report]. 